\title{
Contagious Effects of Customer Misbehavior in Access-Based Services
}

\author{
Tobias Schaefers' ${ }^{1}$, Kristina Wittkowski ${ }^{2}$, \\ Sabine Benoit (née Moeller) ${ }^{3}$, and Rosellina Ferraro ${ }^{4}$
}

(S)SAGE

\begin{abstract}
Customer misbehavior in service settings is problematic for two reasons: (I) because of the direct damage it causes and (2) because of additional negative effects that arise from the contagion of such misbehavior. The authors extend existing theory of customer misbehavior by studying its contagious effect. The investigation focuses on access-based services, defined as transactions in which multiple consumers successively gain temporal, short-term access to a good, while legal ownership remains with the service provider (e.g., car sharing and fashion rentals). Due to the nature of these services, they are especially prone to indirect customer misbehavior, which is directed at the accessed product and occurs in the absence of others. Two online experiments provide the first empirical evidence for a contagiousness of misbehavior and reveal that this effect is driven by customers' perceptions of the social norms among the customer group. Moreover, they indicate that greater strength of the accessed product's brand as well as lower anonymity of the accessed product's owner attenuate contagion. A field experiment shows that an increase in the communal identification among access-based service customers reverses the contagious effect, with customers more likely to remove signs of previous users' misbehavior. The results suggest that access-based service providers should address customer misbehavior by (a) investing in the products they offer access to, (b) establishing more personal relationships with customers, and, foremost, (c) increasing communal identification among customers.
\end{abstract}

\section{Keywords}

customer misbehavior, access-based services, nonownership, social norms, car sharing

\begin{abstract}
Really wanted to like this [Zipcar] but our first experience was not great. Reservation process on-line was pretty painless but the car was disgusting inside and out. Big coffee/hot chocolate spill on the passenger seat, crumbs everywhere and it stank of smoke. This car was dirrrrty and clearly had not been cleaned for several weeks (we are talking old crusty dirt here not new dirt from just one person). (Review from a Zipcar customer on yelp.com)
\end{abstract}

In this product review, the customer is not satisfied with the condition of the vehicle rented through Zipcar. He or she appears to attribute its state of cleanliness to not just one customer but multiple previous customers. Specifically, the customer suspects that the vehicle has not been cleaned for weeks, and dirt has built upon prior dirt. This suggests the possibility that bad behavior by one customer may encourage others to behave in a similar fashion, and that this contagion of misbehavior is based not on observing someone who engages in the behavior but based solely on observing the outcome of prior usage.

The described situation is an example of customer misbehavior, which is the act of deliberately disobeying commonly accepted codes of conduct in a consumption situation by inappropriate handling, damage, or overuse of the product (Fullerton and Punj 2004). Customer misbehavior is a part of the daily business of firms in many sectors (Fisk et al. 2010). The consequences range from costs for handling and recovery (Verhoef et al. 2009) to deleterious effects on employees (Bitner, Booms, and Mohr 1994) to deterioration of other customers' satisfaction (Grove and Fisk 1997).

The contagiousness of customer misbehavior, although conceptualized in previous research (Harris and Reynolds 2003; Verhoef et al. 2009), has not been empirically quantified and validated. Additionally, existing research has focused on misbehavior that occurs in the presence of others and is directed at employees and other customers (Fisk et al. 2010). Examples include verbal or physical abuse, cutting the queue, or unwarranted complaining, all of which we categorize as "direct

\footnotetext{
' TU Dortmund University, Dortmund, Germany

${ }^{2}$ Department of Marketing, School of Business, Aalto University, Aalto, Finland

${ }^{3}$ Roehampton Business School, London, UK

${ }^{4}$ Robert H. Smith School of Business, University of Maryland, College Park, MD, USA
}

\section{Corresponding Author:}

Tobias Schaefers, TU Dortmund University, Otto-Hahn-Str. 6, 44227, Dortmund, Germany.

Email: tobias.schaefers@udo.edu 
misbehavior." Customer misbehavior can also occur in the absence of employees and other customers and be directed at the resources necessary for service delivery (e.g., vandalism; McColl-Kennedy et al. 2009), which we describe as "indirect misbehavior." The present study investigates the contagious effect of such indirect misbehavior.

Although various settings exist in which indirect customer misbehavior can occur, the Zipcar review refers to misbehavior contagion in an access-based service. Such services comprise transactions in which multiple consumers successively gain temporal, short-term access to a good (e.g., Bardhi and Eckhardt 2012; Schaefers, Lawson, and Kukar-Kinney 2015). Examples include car and bicycle sharing (e.g., Zipcar and Capital Bikeshare), short-term rentals of fashion items (e.g., Bag Borrow or Steal), or peer-to-peer platforms in which consumers offer others use of goods they own (e.g., RelayRides and AirBnB). In the context of access-based services, the contagious effect of indirect misbehavior is particularly relevant for several reasons. First, misbehavior directed at resources (i.e., the accessed good) likely leads to malfunctions or a general nonavailability, negatively affecting service delivery for other customers. Second, because customers often use these services in the absence of a service provider representative, the likelihood of misbehavior may be higher. Customers may assume a lower risk of misbehavior detection, which reduces their mental restraints and increases the likelihood of misbehavior (Wirtz and Kum 2004). Third, in some cases, the accessed good passes directly from one customer to the next, without an interim return to the service provider, as in free-floating car sharing services (Firnkorn and Müller 2011). The service provider cannot examine the good after each use in order to eliminate signs of previous misbehavior and thus alleviate a possible contagion. The access-based service context hence offers a good opportunity to investigate the contagiousness of indirect customer misbehavior.

Based on criminology's broken windows theory (Kelling and Coles 1997), we provide empirical support for misbehavior contagion, identify perceived social norms as the mediator, and show that the strength of the accessed product's brand as well as reduced anonymity of the accessed product's owner attenuate contagion. Moreover, our findings reveal that communal identification among customers reverses the contagious effect. From a managerial perspective, our findings support service providers in their efforts to address customer misbehavior.

\section{Conceptual Background}

\section{Customer Misbehavior}

Customer misbehavior is defined as behavior that deliberately violates generally accepted norms of conduct in consumption situations (Fullerton and Punj 2004). It includes shoplifting (e.g., Cox, Cox, and Moschis 1990), cutting the queue (e.g., Moore, Moore, and Capella 2005), illegitimate product returns (e.g., Harris and Daunt 2011), as well as verbal and physical abuse of employees, customers, or company resources (e.g., Bitner, Booms, and Mohr 1994). Such behavior, and the individuals exhibiting it, has also been referred to as deviant customer behavior (Harris and Daunt 2011), dysfunctional customers (Gong, Yi, and Choi 2014), problem customers (Bitner, Booms, and Mohr 1994), or jaycustomers (Lovelock 1994).

Misbehavior appears endemic to customer-firm interactions (Fisk et al. 2010). It may impede business operations through a negative effect on the company, a negative effect on other customers' service experience, and a contagious effect on other customers' behavior. First, misbehavior harms the service provider if company property is damaged and recovery costs are incurred (Verhoef et al. 2009), or if employees are negatively affected in terms of satisfaction, morale, and performance (Bitner, Booms, and Mohr 1994). Second, misbehavior by one customer may reduce other customers' satisfaction (Bitner, Booms, and Tetreault 1990; Grove and Fisk 1997). Third, customers who misbehave might implicitly encourage others to engage in misbehavior (Harris and Reynolds 2003; Verhoef et al. 2009).

This research focuses on the third negative consequence of misbehavior, a contagiousness of one or more customers' misbehavior on other customers, which Harris and Reynolds (2003, p. 153) describe as "domino effects." Although such effects have previously been conceptualized and the qualitative study by Harris and Reynolds (2003) found some supporting evidence, a quantitative empirical investigation is missing. We intend to enhance the understanding of interpersonal effects of customer misbehavior in the context of access-based services.

\section{Access-Based Services}

Access-based services are defined as services that allow customers to access a good, physical facility, network, labor, or space for a defined period of time, in return for an access payment, while legal ownership remains with the proprietor, who is often the service provider (Bardhi and Eckhardt 2012; Lovelock and Gummesson 2004; Schaefers, Lawson, and KukarKinney 2015). The phenomenon is linked to the broader context of collaborative consumption (Botsman and Rogers 2010; Leismann et al. 2013), which also includes transactions that are not market mediated (e.g., swapping and not-forprofit communal sharing). Access-based services have been referred to as nonownership services (Lovelock and Gummesson 2004; Wittkowski, Moeller, and Wirtz 2013), productsharing services (Johnson, Herrmann, and Huber 1998), or product service systems (Mont 2002).

Unlike in an ownership context, customers do not acquire full property rights to the product, but rather obtain temporary access while the burdens of ownership, such as rental and repair responsibilities, remain with the owner (Moeller and Wittkowski 2010; Wittkowski, Moeller, and Wirtz 2013). In most access-based services, manufactured goods or durables constitute the core of the offering (Lovelock and Gummesson 2004). As the expected life span of such goods exceeds the access 
period of a single customer, multiple customers can successively use the provided good. Although access-based services entail shared access to a good, they are not altruistic (Belk 2010). Their use might be influenced by a desire to share, but they are based on an economic exchange of access fees paid by customers (Bardhi and Eckhardt 2012).

Access-based services are not new as renting and leasing have long existed. Yet, they are gaining relevance due to changes in consumers' lifestyles and technological advancements (Bardhi and Eckhardt 2012; Moeller and Wittkowski 2010). Successful companies (e.g., erento.com) capitalize on these trends by offering access to a vast range of goods including musical instruments and bulldozers. A common example of an access-based service is car sharing, in which an owner, whether a service provider or an individual, gives customers access to a car. Recently, the car sharing market has grown and gained momentum from the market entry of car manufacturers, such as Daimler (Crossland 2011).

Access-based service customers engage in three types of interactions. First, they interact with the accessed product, as the product itself is critical to the service exchange (Schaefers 2013). Second, customers interact with the service provider, for instance, when registering or reserving products (Durgee and O'Connor 1995). Third, customers may interact with other users. This interaction may occur directly, when seeing others who use the service (Schaefers 2013), or indirectly via signs of previous usage (Bardhi and Eckhardt 2012). We explore moderators related to these three interactions, as they may offer an opportunity for service providers to influence customer behavior.

\section{Customer Misbehavior in Access-Based Services}

There appears to be a heightened risk of misuse when customers access goods without owning them (Durgee and O'Connor 1995). Similarly, Bardhi and Eckhardt (2012) highlight the frequency of indirect misbehavior in access-based services and find that users exhibit only a minimal sense of responsibility toward the accessed product. Overall, customer misbehavior in access-based services features two unique aspects - the relevance of misbehavior directed at shared assets and the occurrence of indirect misbehavior.

The first particularity relates to the successive access to a good by different customers. A prerequisite for efficient functioning of the access-based service is the responsible behavior of customers. This coincides with responsibilities found in sharing, such as "taking care not to damage shared possessions, not overusing these things ... and cleaning up so that others will find the resources in a similar state of readiness for their own use" (Belk 2010, p. 717). Users of access-based services who fail to fulfill these responsibilities disrupt the consumption order. Our definition of customer misbehavior in access-based services thus spans inappropriate handling, damage, or overuse of the accessed good.

The second particularity is that in access-based services, compared with retail or hospitality settings, the likelihood of indirect misbehavior increases, as products are commonly used without any supervision by service personnel. Free-floating car sharing services, for example, give customers access to a fleet of vehicles. Cars may be parked at any public parking space in the operating area, and customers individually access a car and terminate the rental anywhere they choose, without the service provider checking the vehicle upon its return. Although such business models increase flexibility for customers (Schaefers 2013), service firms face the challenge of assessing the condition of the good. Due to the outlined particularities, accessbased service providers require ways of reducing customer misbehavior contagion. In the following, we therefore propose hypotheses regarding such approaches.

\section{Hypotheses Development}

We next present our theoretical framework for a contagiousness of misbehavior, its mediation via perceived social norms, and the moderation by brand strength, relationship type, and communal identification. An illustration of the hypothesized effects appears in Figure 1.

\section{Contagious Effect of Customer Misbehavior in Access- Based Services}

In general, a person's behavior is contagious if it induces others to act in the same way (Jones and Jones 1992). Contagion has been investigated in services with a focus on emotional contagion between employees and customers, for both positive and negative emotions (e.g., Dallimore, Sparks, and Butcher 2007; Hennig-Thurau et al. 2006; Luong 2005). Previous research also offers evidence of a contagious effect of unethical behavior. Gino, Ayal, and Ariely (2009), for instance, found that observing peers engaged in unethical behavior, such as cheating on a test, increases the observers' level of unethical behavior.

Both emotional contagion in service encounters and contagion of unethical behavior are based on observation of others and thus represent direct misbehavior. To hypothesize the contagiousness of indirect misbehavior, we draw from criminology's broken windows theory (Kelling and Wilson 1982), which predicts contagion of misconduct. The theory postulates that urban decay (e.g., vandalized urban environments) signals previous misconduct and spawns criminal activities; directly witnessing misbehavior is not required. Although some of the implications of broken windows theory for policing have been critically discussed (Harcourt 2009), the theory has found wide application in sociology and social psychology (e.g., Sampson, Morenoff, and Gannon-Rowley 2002; Wilcox et al. 2004). Applied to the context of access-based services, broken windows theory suggests that encountering signs of previous customers' misbehavior should be contagious. The theory argues that misbehavior contagion arises because of changes in perceived social norms. Disordered environmental conditions offer a cue that the behavior leading to such conditions is common and feasible (i.e., is part of the social norms in this 


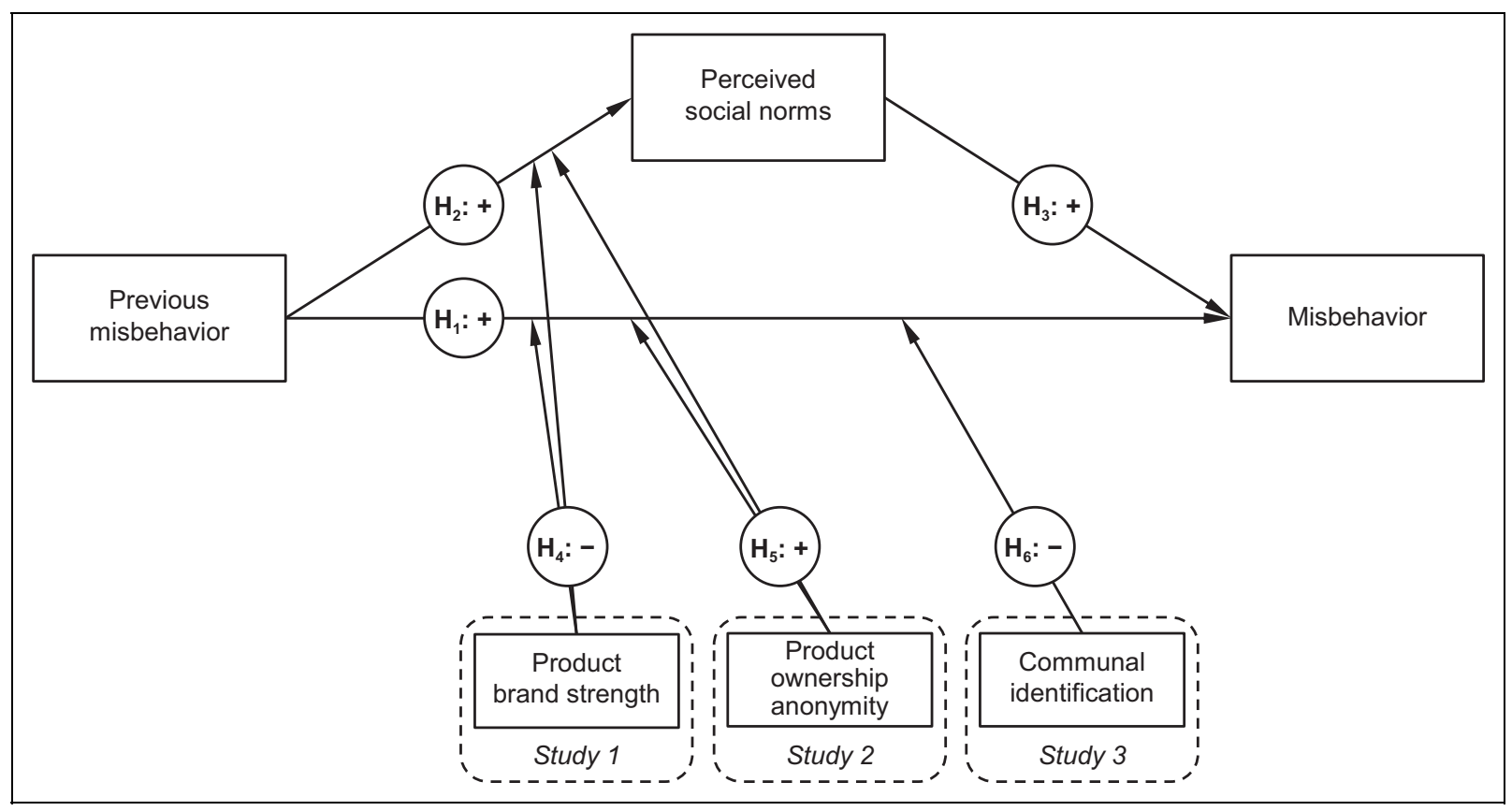

Figure I. Conceptual model.

environment). Exhibiting similar misbehavior is perceived to be normal, which in turn makes misbehavior by this individual more likely. In an empirical test of the theory, Keizer, Lindenberg, and Steg (2008, p. 1684) find support for a contagious effect and conclude that "as a certain norm-violating behavior becomes more common, it will negatively influence conformity to other norms and rules." Specifically, in a series of six field experiments in which the level of disorder in common public spaces was manipulated, the authors found that signs of misbehavior (e.g., graffiti and litter) encouraged others to behave disruptively and led to other inappropriate behavior (e.g., stealing).

Because access-based service settings involve multiple customers who do not necessarily directly interact with each other, the condition of the product will likely lead to inferences about which behaviors are acceptable. Previous misbehavior can be assumed to increase perceptions that the norm is to misbehave. We propose that it is this increase in perceptions that most people engage in misbehavior that results in the contagious effect.

Hypothesis 1: Previous misbehavior (vs. no previous misbehavior) by other customers in an access-based service increases the misbehavior of subsequent customers.

Hypothesis 2: Previous misbehavior (vs. no previous misbehavior) by other customers in an access-based service increases perceptions that the social norm is to misbehave.

Hypothesis 3: Perceptions of social norms mediate the effect of previous misbehavior by other customers in an access-based service on subsequent customers' misbehavior.

\section{The Role of Product Brand Strength for Customer Misbehavior Contagiousness}

The product that customers access is at the core of an accessbased service (Wittkowski, Moeller, and Wirtz 2013). When considering misbehavior, the condition of the product serves as a cue of previous customers' conduct, which varies with each usage. At the same time, there may be other cues that the accessed product sends out which are stable and not affected by each usage, such as the accessed product's brand (Teas and Agarwal 2000). Broken windows theory suggests that the same misbehavior in a nice versus a less nice neighborhood differentially affects perceptions of social norms, and thus contagion (Kelling and Wilson 1982). The nature of a nice neighborhood indicates that misbehavior is an unlikely event and thus influences the extent to which an occurrence of misbehavior is contagious.

Similarly, we predict that the strength of the accessed product's brand moderates perceptions of misbehavior. Providers may offer a number of brands as part of their service. For instance, Zipcar's fleet is comprised of mass-market and premium brands. We propose that a stronger brand (i.e., a brand with a more favorable image) should prompt perceptions similar to that of an upscale neighborhood. Encountering previous misbehavior should thus reduce the perception that such behavior is the norm and reduce the likelihood of subsequent misbehavior.

Hypothesis 4: The strength of the accessed product's brand moderates misbehavior contagion, such that as brand strength increases, the effects of previous misbehavior on subsequent customers' perceptions of social norms and misbehavior are attenuated. 


\section{The Role of Ownership Anonymity for Customer Misbehavior Contagiousness}

According to broken windows theory, anonymity among individuals influences the extent to which signals of previous misconduct are incorporated into observers' perceptions of social norms (Kelling and Coles 1997). For instance, in urban environments, which tend to be characterized by anonymity, it is more likely that disorder leads individuals to perceive misbehavior to be part of the social norms, thereby increasing the chance of similar behavior. In rural environments, on the other hand, anonymity is generally lower and signs of misbehavior are thus less likely to influence perceived social norms and the spreading of disorder.

In their conceptualization of customer misbehavior, Fullerton and Punj (2004) propose that the more impersonal (i.e., anonymous) a company is perceived to be, the more likely misbehavior will occur. The authors argue that with greater social distance between a company and a customer, the former is viewed more as an abstract entity, which reduces the normative barrier to misbehave. Although traditional, market-mediated access-based services are characterized by anonymity between the customer and the service provider, more personal forms of access-based services exist. Peer-to-peer sharing platforms, for instance, offer access to objects owned by other individuals, rather than companies. For such services, customers still pay a fee for accessing an object, making it an equally marketmediated context as professional access-based services; however, the owner of the accessed product is an identified individual instead of an impersonal service provider. As the initiation of service delivery commonly includes virtual or even personal contact between the customer and the owner, such peer-to-peer settings are characterized by a lower degree of anonymity than professional access-based services. This should in turn decrease the likelihood of misbehavior contagion. Thus, we propose that encountering signs of previous misbehavior when accessing a product owned by an anonymous service provider will draw more inferences that such behavior is part of the social norms than when accessing a product owned by an identified individual.

Hypothesis 5: Anonymity of the owner moderates misbehavior contagion, such that the effects of previous misbehavior on subsequent customers' perceptions of social norms and on misbehavior are stronger when the accessed product is owned by an anonymous company than when it is owned by an identified individual.

\section{The Role of Communal Identification for Customer Misbehavior Contagiousness}

According to broken windows theory, the spreading of disorder and crime also depends on interactions among community members and resulting informal control mechanisms (Kelling and Wilson 1982; Xu, Fiedler, and Flaming 2005). Ross and Jang (2000) find that neighborhood disorder and social ties interact; the latter buffer deleterious effects of misbehavior. Sampson, Morenoff, and Gannon-Rowley (2002) reveal that neighborhood ties (i.e., the communal identification among citizens) reduce the negative consequences of misbehavior.

Other research suggests that the communal identification among individuals increases feelings of responsibility and, subsequently, the likelihood of exerting social control on others who misbehave. Muniz and O'Guinn (2001), for instance, identified a shared sense of responsibility as one element of brand communities. Community members feel an obligation to help the other members as well as to ensure the community's survival. This feeling of responsibility among community members leads to disapproval and corrective reactions by those who witness misbehavior, also themed as social control (Chaurand and Brauer 2008). These social control reactions are more likely to be exhibited if the individual who misbehaves (e.g., by littering) is an in-group member, with whom the observer shares a sense of community, compared to an out-group member (Nugier et al. 2009). Since misbehavior in access-based services is likely to occur in the absence of others, there is no possibility for a subsequent customer to exert social control on the individual who misbehaved. When they cannot directly exert social control, individuals may react by removing the signs of misbehavior (Keizer, Lindenberg, and Steg 2013).

These research streams suggest that communal identification among customers should attenuate misbehavior contagion. They even suggest that a high level of community identification can reverse the effect, such that customers who exhibit high communal identification will experience a heightened sense of responsibility to the community, exhibited by correcting the signs of previous misbehavior. As Kozinets et al. (2010) show that community members are well aware of the communal norms underlying interpersonal interactions, we assume that a reversed contagious effect does not operate via changes in perceptions about social norms. Thus, we only predict an effect of communal identification on contagion of misbehavior.

Hypothesis 6: Communal identification moderates misbehavior contagion, such that for customers high in communal identification, previous misbehavior will increase positive behavior toward the accessed product.

\section{Overview of Studies and Scale Development}

We investigate the proposed framework in three studies, all in the context of car sharing. In Study 1, we examine the general contagious effect of previous misbehavior, perceived social norms as the mediating variable, and moderation based on the accessed product's brand strength. In Study 2, we test the accessed product's owner anonymity as a moderator. Studies 1 and 2 involve scenario-based online experiments, Study 3 is a field experiment that investigates whether communal identification among customers of an access-based service leads to reversed reactions to previous misbehavior. 
Journal of Service Research 19(I)

To capture the contagiousness of previous misbehavior in Studies 1 and 2, we created a measure of one's intention to misbehave. The degree to which misbehavior is perceived to be the social norm, employed as the mediator across all three studies, was captured with a measure of perceptions that other customers engage in such behavior. We developed these two new multi-item measures using established scale development guidelines (Netemeyer, Bearden, and Sharma 2003). In Study 3 , misbehavior is measured by observing actual behavior in the field experiment. For the sake of simplicity, we uniformly refer to the dependent variables as "misbehavior."

In order to identify common misbehaviors for the measures, we conducted semistructured personal interviews with 14 customers of a car sharing service in Austin, TX (eight females; 21 to 48 years old) recruited via a post on the company's Facebook page. The interviews, which lasted an average of 36 minutes, were audio recorded and transcribed. We collected responses on various topics, including usage motives, identification with the company, and recommendation behavior, as well as whether participants had ever encountered signs of previous customers' misconduct and what they experienced in particular. We then conducted a content analysis that followed a phenomenological approach (Smith, Flowers, and Larkin 2009). Specifically, one author identified accounts of misbehavior from the transcripts, from which, three authors identified specific deviant behaviors. Additionally, we considered the quotes provided by Bardhi and Eckhardt (2012) from their interviews with Zipcar customers and the items from the Daunt and Harris's (2011) scale developed for an in-store hospitality setting. We combined these insights to derive a set of 15 items that tap into different aspects of misbehavior, including recklessness (e.g., soiling vehicles), dishonesty (e.g., not reporting damages), and deliberate violation of existing norms (e.g., deliberate mishandling of vehicles). Expert judgments and qualitative pretests helped us refine and reduce the scale to 5 items (see Appendix A). To assess respondents' perceptions of social norms (i.e., whether or not others misbehave), we adapted the 5 items to refer to expectations about others' misbehavior. In a pilot study with 47 undergraduate students, both scales exhibited satisfactory psychometric properties. An exploratory factor analysis of all items revealed two factors. All items loaded high on their designated construct (loadings between .633 and .896) but low on the rival construct (loadings between .038 and .391). These results indicate that misbehavior and perceived social norms represent two distinct constructs. In the two online studies, confirmatory factor analyses supported the validity and reliability of both scales.

An alternative explanation for misbehavior contagion is that subsequent users are engaging in negative reciprocity. In other words, they may believe that retribution is the correct and proper response to unfavorable treatment (Eisenberger et al. 2004). If this is the case, users respond to misbehavior from prior users by misbehaving toward subsequent users. We measure the tendency to engage in negative reciprocity and use it as a covariate in the analyses to show that our predicted effects occur over and above any desire to reciprocate bad behavior.

\section{Study I \\ Study Design and Method}

This study was a 2 (previous misbehavior: yes, no) $\times 2$ (brand strength: low, high) between-subjects experiment. The context for the experiment involved car sharing. We employed a self-administered online questionnaire and recruited a sample of 363 German respondents through the online panel of a market research firm that provided small monetary incentives for participation. The limitations created by using panel participants as respondents-such as recruitment bias and conditioning bias-were addressed by the panel provider. Data were collected based on quota sampling, such that the overall sample and each experimental group were balanced in terms of gender (female $=52.3 \%$ ) and age $\left(M=41.84\right.$ years, age $\mathrm{e}_{\min }=18$ years to age $\mathrm{e}_{\max }=65$ years $)$. We accounted for any gender or age differences by including both variables as covariates in the analyses.

Procedure. Participants were randomly assigned to one of the four experimental conditions. To ensure that respondents allocated enough attention and to create trust, the survey began with a filler task. Next, respondents' tendency for socially desirable responding (Crowne and Marlowe 1960) was measured to control for such effects, as well as participants' tendency toward negative reciprocity. Participants were then presented with a text-based and picture-based scenario about a fictional free-floating car sharing service offering access to cars of a specific brand. They were asked to imagine being a customer who is about to pick up a reserved car. The vehicle's condition and brand differed according to experimental condition (see Appendix B for a detailed description of the stimuli). Participants then completed the response items.

We manipulated previous misbehavior by showing participants pictures of either a dirty and damaged car (previous misbehavior) or a clean and not damaged car (no previous misbehavior). The images were pretested to ensure a valid manipulation and a manipulation check was included at the end of the study. Specifically, participants rated previous customer's behavior using a set of 5 items (e.g., The previous user has treated the car responsibly; $\alpha=.98 ; 5$-point Likert-type scale). Respondents in the misbehavior conditions perceived previous customers to have behaved significantly worse than those in the no misbehavior conditions $\left(M_{\text {prev. misb }}=1.47 ; M_{\text {no prev. misb. }}=\right.$ $4.20 ; F(3,359)=417.64 ; p<.01)$.

To manipulate brand strength, the vehicle's brand was mentioned in the text, and brand logos were displayed. We conducted a pretest to identify two car brands that were equally well known but had significantly different brand strength perceptions. Audi and Daihatsu served as the strong and weak brands, respectively. As a manipulation check, we measured 
respondents' brand strength perceptions with 4 items (e.g., "reliable/unreliable"; $\alpha=.96$ ) on a 5-point semantic differential scale (Dodds, Monroe, and Grewal 1991). Audi was indeed perceived as a stronger brand than Daihatsu $\left(M_{\text {strong brand }}=\right.$ $\left.4.42 ; M_{\text {weak brand }}=2.83 ; F(3,359)=205.07 ; p<.01\right)$.

Measures. All measures appear in Appendix A. Misbehavior and perceived social norms were measured with the 5-item 5 -point scales described previously. To reduce social desirability bias, the perceived social norms measure came before inquiring about respondents' intended behavior. Both scales exhibited satisfactory reliability scores (misbehavior: $\alpha=$ .81 , construct reliability $[\mathrm{CR}]=.83$; perceived social norms: $\alpha=.80, \mathrm{CR}=.86$ ). The average variance extracted (AVE) exceeded .5 (Fornell and Larcker 1981) for both misbehavior $(\mathrm{AVE}=.50)$ and perceived social norms $(\mathrm{AVE}=.56)$. Moreover, AVE exceeded the squared correlation between both constructs $\left(r^{2}=.18\right)$, indicating discriminant validity (Fornell and Larcker 1981). Furthermore, an assessment of participants' responses to the socially desirable response style items indicated neither a significant correlation with perceived social norms nor with misbehavior. Respondents' tendency to engage in negative reciprocity, included as a covariate, was measured with a 4 -item scale $(\alpha=.85)$ based on Eisenberger et al. (2004).

\section{Results}

In order to investigate the contagion of previous misbehavior as well as the mediation via perceived social norms and the moderation by the accessed product's brand strength, we analyzed the data with PROCESS (version 2.1; Hayes 2013), which uses ordinary least squares regression and bootstrapping procedures for estimating direct and indirect effects. PROCESS estimates mediation, moderation, and conditional processes (i.e., a combination of moderation and mediation) with dichotomous independent variables. The independent variables in the regression equations were the covariates (i.e., negative reciprocity, gender, and age), previous misbehavior, brand strength, and the previous misbehavior $\times$ brand strength interaction.

The regression on misbehavior revealed a significant effect of previous misbehavior $(\beta=.39, t(356)=5.63$, $p<.01)$, a marginally significant effect of brand strength $(\beta=-.13, t(356)=-1.87, p=.06)$, and a marginally significant interaction $(\beta=-.25, t(356)=-1.76, p=.08)$. Negative reciprocity $(\beta=.19, t(356)=4.67, p<.01)$ and age $(\beta=-.01, t(356)=-2.75, p<.01)$ each exerted a significant, but small, effect, while gender was not significant $(\beta$ $=.11, t(356)=1.38, p=.17)$. These results indicate that, even when controlling for individual proneness for revenge, previous misbehavior is contagious, but the effect differs by brand strength, providing support for Hypotheses 1 and 4 (see Figure 2). When the service was offered by a weak brand, previous misbehavior led to increased misbehavior $\left(M_{\text {no prev. misb. }}=1.46\right.$ versus $M_{\text {prev. misb. }}=2.05 ; \beta=.52$, $t(356)=5.17, p<.01)$. This was also the case when the service was offered by a strong brand $\left(M_{\text {no prev. misb. }}=\right.$ 1.47 versus $M_{\text {prev. misb. }}=1.74 ; \beta=.27, t(356)=2.76, p<$ $.01)$, but the effect was weaker.

Hypothesis 2 predicts that previous misbehavior increases the perception that the norm is to misbehave. A regression analysis on perceived social norms showed a significant effect of previous misbehavior $(\beta=.43, t(356)=7.70, p<$ $.01)$, brand strength $(\beta=-.19, t(356)=-3.40, p<.01)$, and the interaction $(\beta=-.35, t(356)=-3.13, p<.01)$. Negative reciprocity exhibited a significant, yet weak, influence $(\beta=$ $.08, t(356)=2.45, p<.05)$. Neither gender $(\beta=-.01$, $t(356)=-.15, p=.89)$ nor age $(\beta=-.003, t(356)=$ $-1.28, p=.20$ ) was significant. As with contagion, the results indicate that the effect of previous misbehavior on perceptions of social norms depends on brand strength (Hypothesis 4). When the accessed product was of a weak brand, the enhancing effect was stronger $\left(M_{\text {no }}\right.$ prev. misb. $=$ 2.96 versus $M_{\text {prev. misb. }}=3.60 ; \beta=.61, t(356)=7.57, p<$ $.01)$, than when the accessed product was of a strong brand $\left(M_{\text {no prev. misb. }}=2.95\right.$ versus $M_{\text {prev. misb. }}=3.21 ; \beta=.26$, $t(356)=3.26, p<.01)$.

The conditional process analysis (see Figure 3 ) revealed that perceived social norms mediate the contagious effect of previous misbehavior for weak $(B=.14$, standard error $[S E]=.05,99 \%$ bootstrap confidence interval $[\mathrm{CI}]=[.03$, $.31]$ ) and for strong brands ( $B=.06, S E=.03,99 \%$ bootstrap $\mathrm{CI}=[.01, .15])$. For both levels of brand strength, the $99 \% \mathrm{CI}$ excludes zero, indicating a mediating effect of perceived social norms at $p<.01$, providing support for Hypothesis 3. There was a difference in the size of the direct effect of previous misbehavior on misbehavior between weak ( $\beta=$ $.38, t(355)=3.54, p<.01)$ and strong $(\beta=.21, t(355)=$ $2.16, p<.05)$ brands. In sum, the contagious effect operates through perceived social norms and is stronger when customers access a weak brand.

\section{Discussion}

In line with Hypothesis 1, previous misbehavior increases respondents' misbehavior intentions, thereby providing support for the conceptualized contagion. This effect is evident even when controlling for people's tendency to want to reciprocate prior misbehavior. Additionally, prior misbehavior increases the extent to which others are expected to misbehave (i.e., misbehavior perceived as part of the social norms [Hypothesis 2]). The mediation analysis shows that increased perceptions that others engage in misbehavior drive contagion (Hypothesis 3), supporting the underlying assumptions derived from broken windows theory. Even when customers only indirectly experience misbehavior of others, it negatively influences their perception of the norms among the customer group and thereby affects their own behavioral intentions accordingly. The strength of the accessed product's brand acts as a buffer for the contagiousness of previous misbehavior (Hypothesis 4). This supports the assumption that the brand of the accessed product 


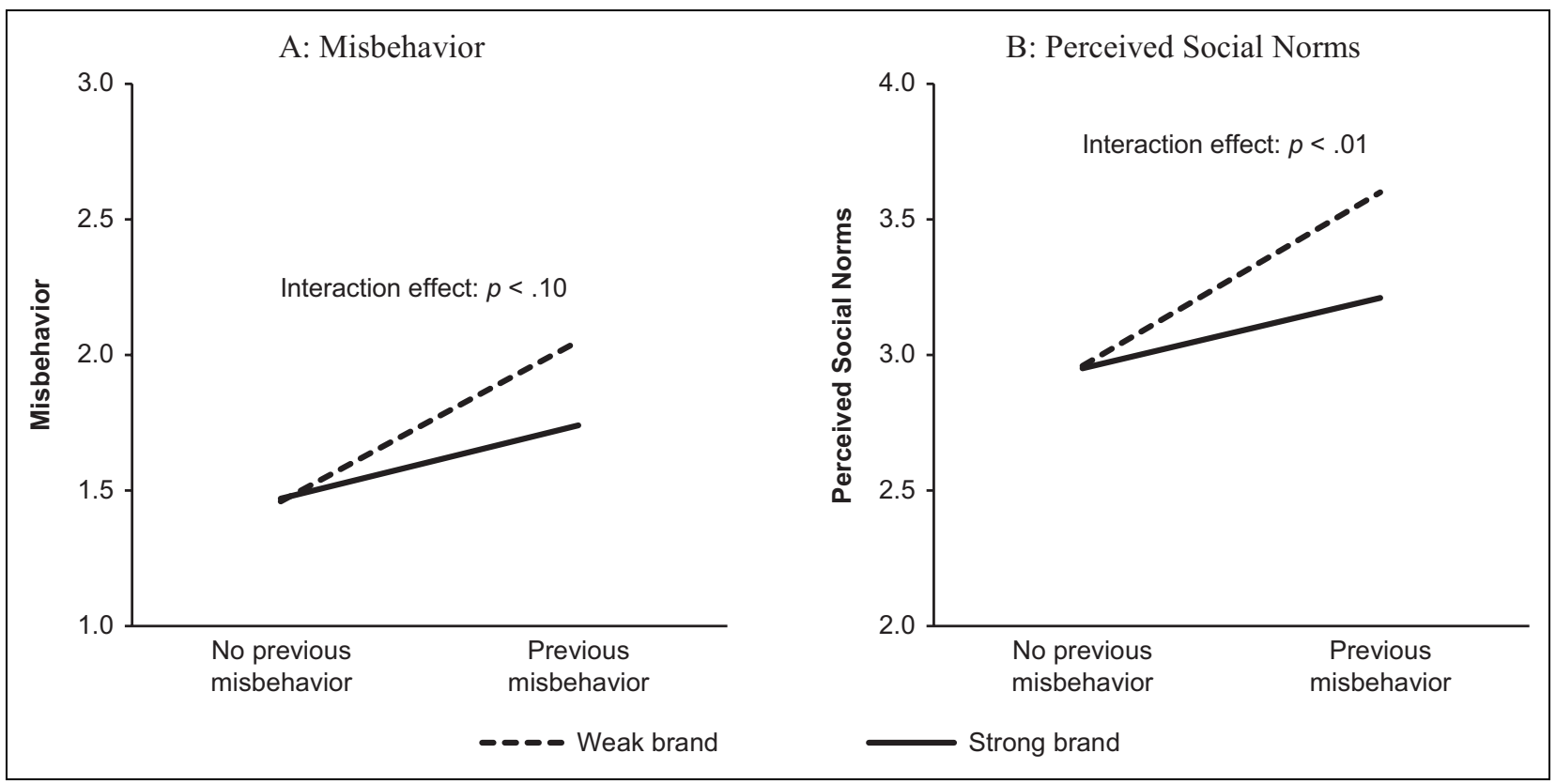

Figure 2. Study I: Misbehavior and perceived social norms by previous misbehavior and brand strength.

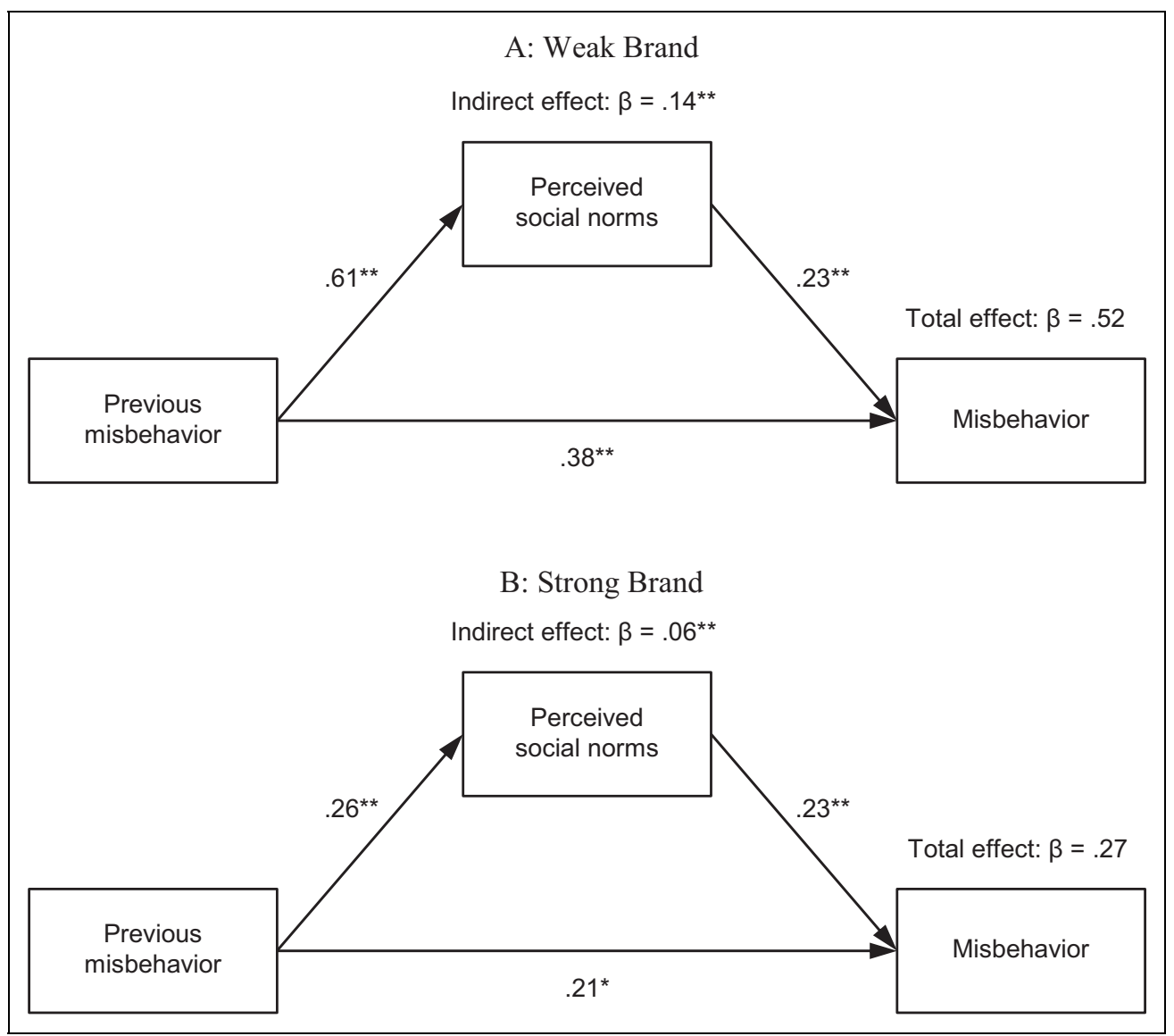

Figure 3. Study I: Conditional direct and indirect effects of previous misbehavior on misbehavior for weak and strong brand. $* * p<.0 \mathrm{I}$. $* p<.05$. 
serves as a stable cue. Hence, brands that are perceived positively reduce contagion.

\section{Study 2}

In Study 2, we investigate whether the anonymity of the accessed product's owner differentially affects misbehavior contagion (Hypothesis 5). Furthermore, we again test the basic assumptions regarding contagiousness and the role of perceived social norms (Hypotheses 1-3).

\section{Study Design and Method}

The study was a 2 (previous misbehavior: yes, no) $\times 2$ (anonymity of ownership: anonymous, identified owner) betweensubjects experiment, again in the context of car sharing. Data were collected among the same online panel; however, none of the participants in Study 2 had participated in Study 1. The sample consisted of 352 respondents, balanced in terms of gender (female $=51.4 \%)$ and age $\left(M=41.16 ;\right.$ age $_{\min }=18$ years to $\operatorname{age}_{\max }=65$ years).

Procedure. Similar to Study 1, after random assignment to an experimental condition, participants completed an unrelated filler task and answered the items measuring socially desirable responding and tendency to engage in negative reciprocity. Next, a text-based and picture-based scenario asked them to imagine gaining short-term access to a car, with differences in the stimuli according to experimental condition (see Appendix B). Participants then completed the response items.

The pictures from Study 1, without the brand logo, served to manipulate previous misbehavior. The manipulation was checked with the same set of items $(\alpha=.98)$. It was successful, as respondents in the previous misbehavior conditions perceived the behavior of prior customers as significantly worse than those in the no misbehavior conditions $\left(M_{\text {prev. misb. }}=\right.$ $\left.1.52 ; M_{\text {no prev. misb. }}=4.23 ; F(3,348)=516.55 ; p<.01\right)$.

To operationalize ownership anonymity, we created two contrasting scenarios. In the anonymous ownership condition, respondents read that they were customers of a fictional free-floating car sharing service and were about to start using a vehicle. For the identified ownership condition, respondents read that they were members of a fictional peer-topeer car sharing platform and were about to pick up a car that another member was renting out; they would thus meet with the individual owning the vehicle to start the rental. These scenarios were pretested for understanding of the manipulation.

Measures. We measured misbehavior $(\alpha=.79, \mathrm{CR}=.83$, $\mathrm{AVE}=.49)$, perceived social norms $(\alpha=.80, \mathrm{CR}=.85$, $\mathrm{AVE}=.54)$, and negative reciprocity $(\alpha=.84, \mathrm{CR}=$ .85 ; $\mathrm{AVE}=.58)$ using the previously described scales. Comparison with the squared correlation between the two focal constructs $\left(r^{2}=.15\right)$ indicated adequate discriminant validity of the scales. Social desirability did not correlate with the responses to these two scales.

\section{Results}

To analyze the data, we again used PROCESS. The regression analysis on misbehavior showed significant effects of previous misbehavior $(\beta=.33, t(345)=4.66, p<.01)$, ownership anonymity $(\beta=-.24, t(345)=-3.38, p<.01)$, and the interaction term $(\beta=-.30, t(345)=-2.14, p<.05)$, supporting Hypotheses 1 and 5 (see Figure 4). Negative reciprocity $(\beta=.15, t(345)=3.38, p<.01)$ and age $(\beta=-.01$, $t(345)=-2.40, p<.05)$ exerted a significant but weak effect on misbehavior. No significant influence of gender $(\beta=.06$, $t(345)=.84, p=.40$ ) was evident. The results indicate that previous misbehavior is contagious but that the effect differs by ownership anonymity (see Figure 4). When the accessed product was owned by an anonymous service provider, previous misbehavior increased misbehavior $\left(M_{\text {no prev. misb. }}=1.61\right.$ versus $\left.M_{\text {prev. misb. }}=2.10 ; \beta=.48, t(345)=4.75, p<.01\right)$. When the accessed product was owned by an identified individual, however, the increase was only marginally significant $\left(M_{\text {no prev. misb. }}=1.52\right.$ versus $M_{\text {prev. misb. }}=1.71 ; \beta=$ $.18, t(345)=1.81, p=.07)$.

The regression analysis on perceived social norms showed significant effects of previous misbehavior $(\beta=.39, t(345)$ $=6.35, p<.01)$, ownership anonymity $(\beta=-.19, t(345)=$ $3.04, p<.01)$, and the interaction term $(\beta=-.46, t(345)=$ $-3.77, p<.01)$. Negative reciprocity exerted a weak effect $(\beta=.15, t(345)=3.89, p<.01)$, while neither gender $(\beta$ $=.06, t(345)=1.02, p=.31)$ nor age $(\beta=-.001, t(345)$ $=-.28, p=.78)$ had an effect. The results indicate that the effect of previous misbehavior on perceived social norms differs by ownership anonymity. The effect of previous misbehavior on the perception that misbehavior is part of the social norm was significant when the owner of the accessed product was an anonymous service provider $\left(M_{\text {no }}\right.$ prev. misb. $=2.74$ versus $\left.M_{\text {prev. misb. }}=3.37 ; \beta=.62, t(345)=7.06, p<.01\right)$, but was only marginally significant when the accessed product was owned by an identified individual $\left(M_{\text {no prev. misb. }}=2.80\right.$ versus $\left.M_{\text {prev. misb. }}=2.95 ; \beta=.16, t(345)=1.85, p=.07\right)$.

The conditional process model estimation, depicted in Figure 5, revealed that perceiving misbehavior as the social norm mediates misbehavior contagion for both anonymous $(B=.16, S E=.04,99 \%$ bootstrap $C I=[.07, .26])$ and identified product ownership $(B=.04, S E=.02,95 \%$ bootstrap $\mathrm{CI}=[.003, .09])$. When comparing the two ownership anonymity conditions, the contagious effect operates through perceived social norms; however, the indirect effect is stronger for anonymous ownership than for identified ownership. Thus, Hypothesis 5 was supported. In addition to the indirect effect of previous misbehavior on subsequent misbehavior via perceived social norms, the direct effect was significant for anonymous product ownership $(\beta=.32, t(344)=3.07$, $p<.01)$, but not for identified ownership $(\beta=.14, t(344)$ $=1.43, p=.16)$. 


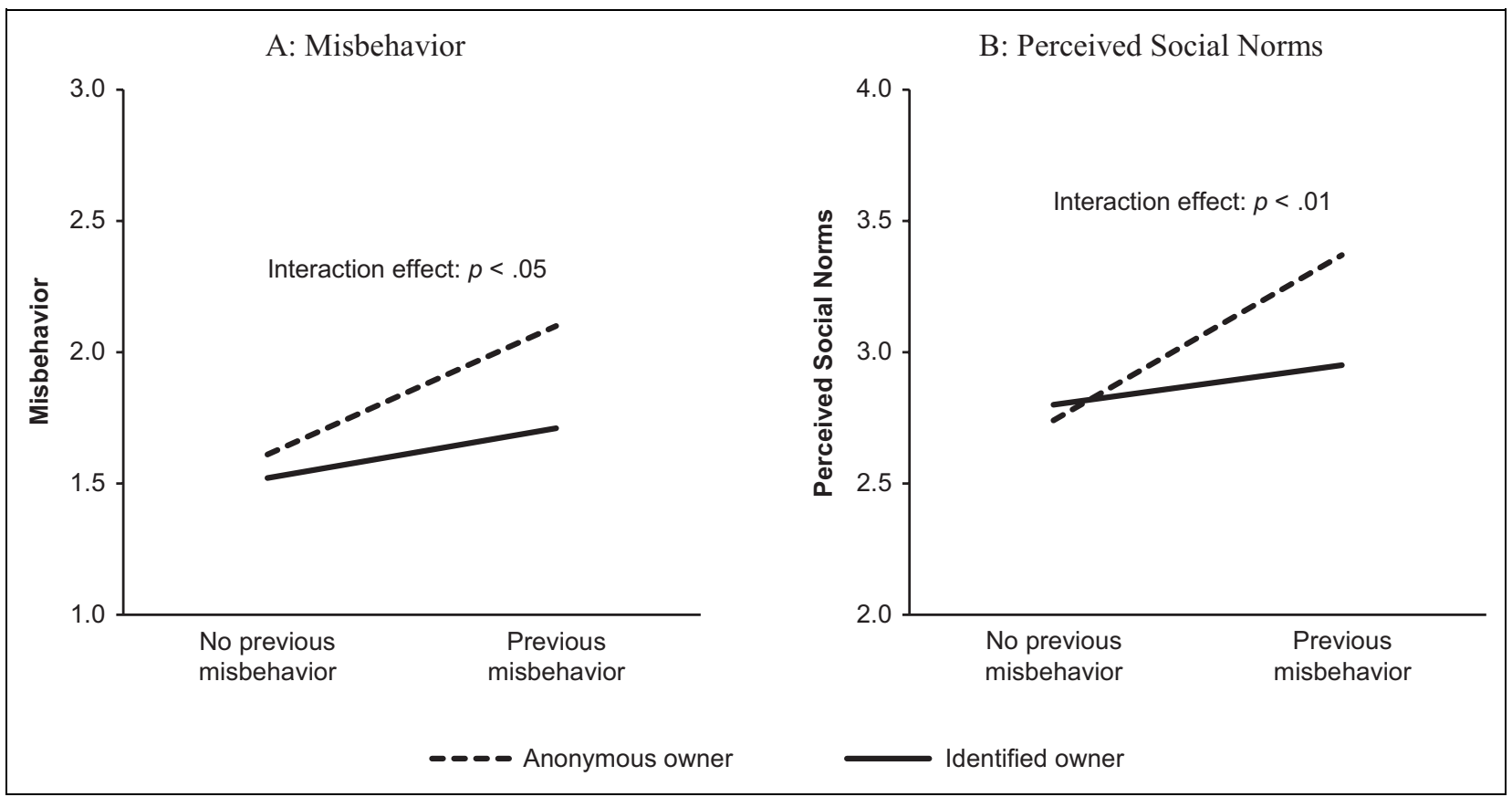

Figure 4. Study 2: Misbehavior and perceived social norms by previous misbehavior and ownership anonymity.

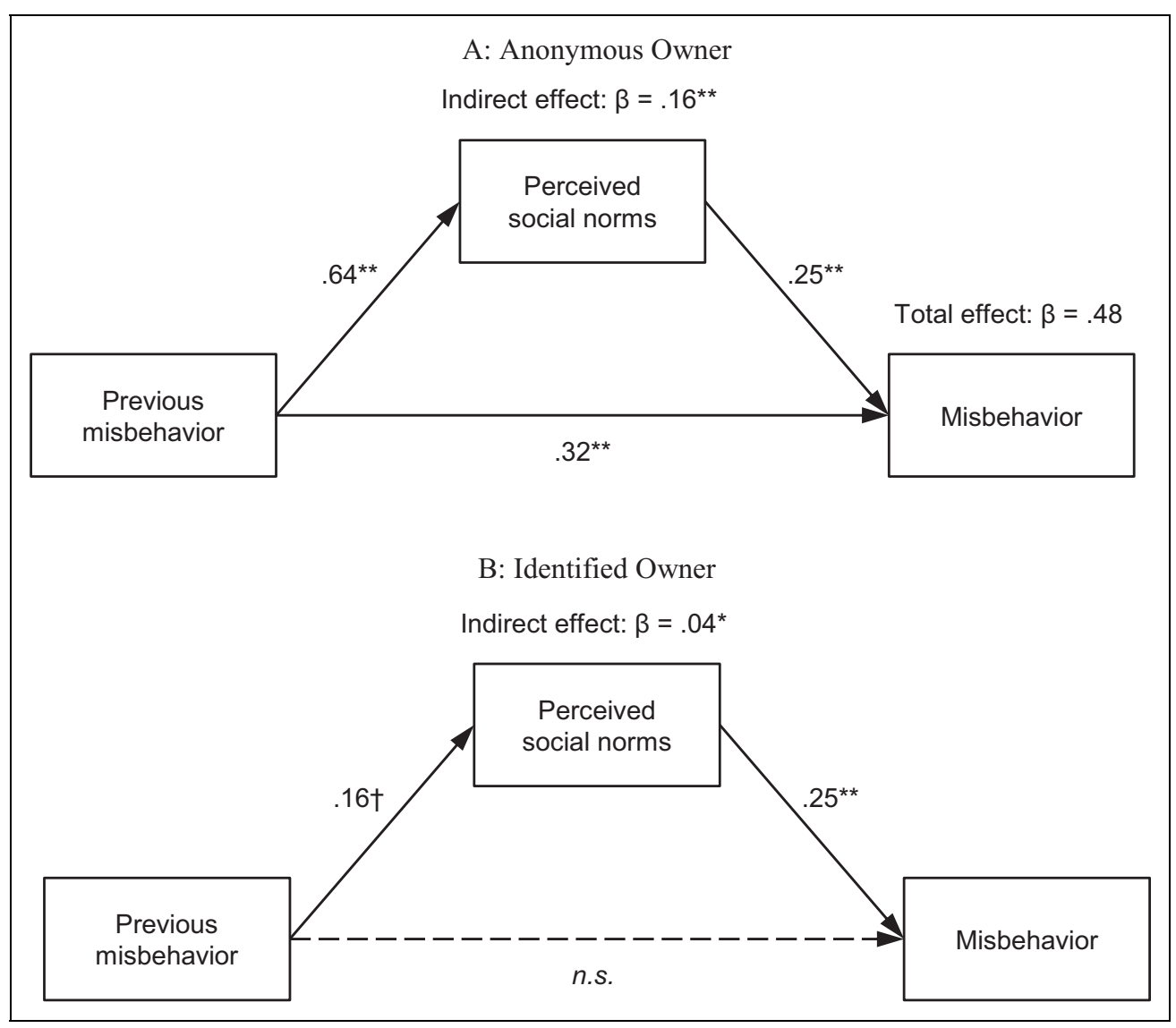

Figure 5. Study 2: Indirect effect of previous misbehavior on misbehavior. $*_{p}^{*}<.01 . *_{p}<.05 . \dagger p<.1$. 


\section{Discussion}

In line with the findings from Study 1, previous misbehavior increases subsequent misbehavior (Hypothesis 1) and leads to a stronger perception of misbehavior being the social norm, which mediates its contagion (Hypotheses 2 and 3). At the same time, the anonymity of the accessed product's owner moderates the relationship (Hypothesis 5). The results support the assumption that encountering signs of previous misbehavior in a more anonymous service relationship leads to a greater perception of misbehavior being part of customers' social norms and thus to acting in similar ways. It is notable that in less anonymous settings where the owner of the accessed product is an identified individual, the effect of previous misbehavior is almost offset.

\section{Study 3}

Customers of an access-based service may interact with the accessed product, the service provider, and other customers. After having investigated the first two aspects, Study 3 tests the hypothesis that the communal identification among customers also affects the contagiousness of previous misbehavior. We specifically test whether greater communal identification increases responsibility and thus reverses misbehavior contagion (Hypothesis 6).

\section{Study Design and Method}

The study included one manipulated between-subjects factor (previous misbehavior: yes, no) and one measured variable (communal identification). In contrast to the first two studies, we collected data in a field experiment. Because of the nature of access-based services, the study could not be conducted in a strictly public environment as was done in Keizer, Lindenberg, and Steg (2008). We utilized an already existing car sharing service. We recruited 41 students (female $=31.7 \% ; M_{\mathrm{age}}=$ 22 years, age $_{\min }=18$ years to age max $_{\max }=31$ years) at a German university who were registered customers of a local car sharing service with vehicles available near campus. Although there will be differences in the extent to which participants vary in their level of communal identification, this setting is likely to result in a sample of participants with generally higher levels of communal identification, as the students are enrolled in the same university and are customers of the same service. However, as our primary intention was to show the relative impact of communal identification, we deemed it as an appropriate study setting.

Procedure. When advertising the study, the true intention was disguised by telling students that they would assess the car sharing service based on individual test-drives, in return for extra class credit. Participants were required to reserve the car sharing vehicle for a one hour time slot.

One week prior to the test-drive, each participant completed an online questionnaire. In addition to filler tasks, this survey prior to the test-drive measured participants' tendency to engage in negative reciprocity, levels of altruism, and communal identification with other customers of the service. On the day of the test-drive, participants arrived individually at an office on campus 15 minutes prior to their reserved time period. To ensure similar driving times, each participant completed a standardized task. Specifically, each student was informed by one of the authors that they would deliver documents to a different campus and then return to the initial starting point. They were given the documents, a printed map of their destination, a bottle of water, and two small bags of candy. All of these items could contribute to misbehavior toward the car. Participants then walked to the vehicle and began the test-drive. After the test-drive, they were asked to return to the office to complete another survey. In addition to filler measures of attitudes and satisfaction toward the car sharing service, this survey assessed participants' perceived social norms and included the manipulation check.

Two assistants, unaware of the research hypotheses, prepared the vehicle according to the randomly determined experimental condition. In the no previous misbehavior condition, the vehicle interior was clean. In the previous misbehavior condition, two empty water bottles as well as a defined number of candy wrappers and crinkled sheets of paper were placed in the vehicle. As the participant was completing the survey after the test-drive, the assistants evaluated the condition of the car's interior, took four pictures from standardized angles for later independent judgment, and prepared the vehicle for the next participant.

The manipulation of previous misbehavior was checked with the same set of items as in the previous studies $(\alpha=.97)$ in the survey after the test-drive. Participants in the previous misbehavior condition perceived the behavior of prior customers as significantly worse than those in the no misbehavior condition $\left(M_{\text {prev. misb. }}=2.58 ; M_{\text {no prev. misb. }}=\right.$ $4.42 ; F(1,39)=35.72 ; p<.01)$, indicating that the manipulation worked as intended.

Measures. Misbehavior was measured as the observed condition of the vehicle after usage, indicated on a 5-point scale $(1=$ in a better condition, $3=$ unchanged, $5=$ in a worse condition); a higher number indicates greater misbehavior. To test the reliability of the assistants' observations, two $\mathrm{PhD}$ students not involved in the research assessed the condition of the vehicle based on the photos for a subsample of observations. They viewed the photos of the vehicle's interior before and after the rental and rated its condition on the same 5-point scale for five randomly selected participants. All judgments were consistent with the assistants' observations.

In the survey prior to the test-drive, negative reciprocity was assessed with the previously described scale $(\alpha=.77)$. Communal identification was measured with a 4 -item scale $(\alpha=$ .74; Rindfleisch, Burroughs, and Wong 2009). Participants' level of altruism, serving as an additional control variable, was measured using 4 items $(\alpha=.70)$ based on the scale by 
Rushton, Chrisjohn, and Fekken (1981). In the survey after the test-drive, perceived social norms $(\alpha=.70)$ were captured with the same scale as in the previous studies.

\section{Results}

Data analysis again used PROCESS. The independent variables in the regression equations were the covariates (i.e., negative reciprocity, altruism, gender, and age), previous misbehavior, communal identification, and the previous misbehavior $\times$ communal identification interaction. Communal identification was mean-centered.

The regression on observed misbehavior showed significant effects of previous misbehavior $(\beta=-.59, t(33)=-2.37$, $p<.05)$, communal identification $(\beta=-.36, t(33)=-2.35$, $p<.05)$, and the interaction $(\beta=-.79, t(33)=-2.59, p<$ .05 ) (see Figure 6). A spotlight analysis (Irwin and McClelland 2001) revealed no effect of previous misbehavior among participants with low communal identification $(-1 S D ; \beta=.01$, $t(33)=.01, p=.99)$. In contrast, encountering previous misbehavior led participants with high communal identification $(+1 \mathrm{SD})$ to leave the accessed product in a better condition than before $(\beta=-1.19, t(33)=-3.59, p<.01)$. We used the Johnson-Neyman technique to determine the value of communal identification at which observed behavior is no longer significantly different across the level of previous misbehavior (Johnson and Fay 1950). This occurs when (mean-centered) communal identification is equal to -.10 . In other words, previous misbehavior increased participants' responsibility at values of communal identification above -.10 , but had no effect below this value.

The contagious effect of previous misbehavior found in Studies 1 and 2 was not replicated, which we discuss next. However, these results provide evidence for a reversed contagion for customers with high communal identification, thereby supporting Hypothesis 6.

\section{Discussion}

Study 3 aimed to understand the role of communal identification among customers of an access-based service on misbehavior contagion. Further, by conducting a field experiment, we intended to increase the external validity of our findings. On the one hand, the results show that high communal identification reverses contagion, as such customers exhibited responsible behavior by removing the remains of previous customers' misbehavior, providing support for Hypothesis 6. On the other hand, when communal identification was low, no contagion was found. Although customers who do not identify with the community left the remains of previous customers' misbehavior unchanged, they did not exhibit misbehavior themselves. We believe that we can explain this seemingly contradictory result.

First, even though the sample included participants qualified as low in communal identification compared to the sample mean, all participants exhibited a relatively high

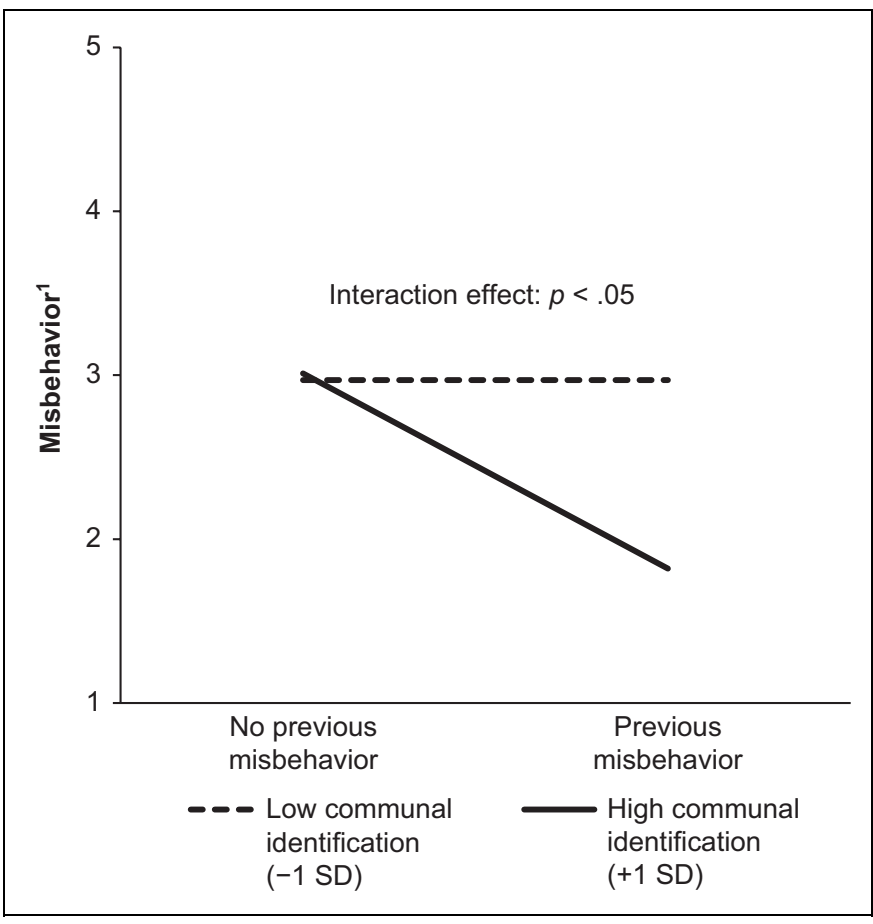

Figure 6. Study 3: Misbehavior by previous misbehavior and communal identification.

Note. (I) Misbehavior was measured by assessing the condition of the vehicle $(I=$ better than before, $3=$ unchanged, and $5=$ worse than before) .

communal identification, with a mean value significantly above the scale midpoint $(M=4.15, S D=.68, p<.01)$. Thus, even those with low communal identification are likely to identify more with fellow customers than consumers in the broader population. The reason for this sample characteristic is that participants all belonged to the same university where they know that other students are also members of the service. Additionally, while the setup of the field experiment prevented participants from meeting during the study, they were likely aware that previous customers were fellow students who also participated in the study, which may have led them to be less inclined to misbehave. In contrast, the participants in Studies 1 and 2 were recruited via a market research firm and thus neither knew each other nor had an awareness of other customers of the fictional car sharing service. They likely would exhibit greater variance in communal identification. Second, communal identification was measured, which may generate dampened effects relative to a manipulation of communal identification. It is possible that manipulating communal identification would have led to a contagious effect for the low communal identification participants. Third, the brand of the accessed product, as evidenced in Study 1, could have further attenuated contagion. The vehicles that participants used for the test-drives were from the German car brand Opel. In the pretest conducted for Study 1 , this brand was evaluated as weaker than the Audi brand $\left(M_{\text {Opel }}=3.34, M_{\text {Audi }}=4.87, t=-21.70, p<.01\right)$, but 
stronger than the Daihatsu brand $\left(M_{\text {Daihatsu }}=1.94, t=15.26\right.$, $p<.01)$. The relative strength of the brand could have attenuated the effect of contagion. The field study setting did not allow us to control for any effect of brand strength.

We ran a regression on perceived social norms, which showed only a significant effect of previous misbehavior $(\beta=.43, t(33)=2.09, p<.05)$. Irrespective of communal identification, participants had a stronger perception that misbehavior is part of the social norm when they encountered previous misbehavior $(M=3.69)$ than when they were not exposed to it $(M=3.32)$. Thus, while the misbehavior manipulation did affect low identifiers' perceptions of social norms, it seems that the effect was not strong enough to carry over to actual misbehavior, which we attribute to the nature of this specific setup.

\section{General Discussion}

Customers increasingly use access-based services that let them forgo ownership and enjoy temporary access to goods. The nature of such services, however, makes them prone to customer misbehavior, which can have far-reaching consequences by affecting subsequent customers' behavior. Although researchers have largely disregarded misbehavior contagion, empirical evidence for such an effect as well as the underlying processes and moderators is an essential prerequisite for identifying means to reduce the spreading of customer misbehavior.

In the first two studies, we found that encountering indirect misbehavior by others was contagious. In line with the assumptions of broken windows theory, this spreading of misbehavior was found to be partly explained by how previous misbehavior influences the perception customers have about social norms. The findings show that the extent to which customers think that misbehavior is part of the social norm mediates the contagious effect.

Study 1 focused on the moderating role of a stable characteristic of the accessed product. This potential lever is especially relevant, as the product that customers gain access to is at the core of such a service and thus directly influences the service experience. The results revealed that greater strength of the accessed product's brand attenuates the misbehavior contagion. In line with broken windows theory, a strong brand is a cue that is incongruent to misbehavior and thereby buffers customers' perception that misbehavior is part of the social norm.

Study 2 focused on the anonymity of the accessed product's owner as a moderator. This was based on the assumption that anonymity increases the extent to which previous misbehavior leads to a deterioration of perceived social norms and thereby enhances the spreading of subsequent misbehavior. We found supporting evidence for such a moderation; misbehavior contagion was found to be stronger in an anonymous setting with the accessed product's owner being an impersonal service provider than in a setting where the owner was an identified individual.
The focus of Study 3 was on the moderating role of communal identification among customers. Specifically, we tested whether among customers high in communal identification, experiencing previous misbehavior increases responsible behavior. We found support for such a reversed contagious effect of misbehavior.

\section{Theoretical Contributions}

We respond to calls to investigate the processes underlying customer misbehavior (e.g., Fisk et al. 2010; Harris and Reynolds 2003). To the best of our knowledge, misbehavior contagion has been conceptualized on a general level (e.g., Harris and Reynolds 2003; Verhoef et al. 2009) but has not been empirically demonstrated. We address this gap using experimental studies that rely on both self-reported data and observed behavior, thereby going beyond common approaches (Fisk et al. 2010). With broken windows theory, we provide a theoretical foundation that specifically considers perceived social norms as an underlying driver of contagion.

Second, we contribute by investigating the negative effect of indirect misbehavior (i.e., occurring in the absence of others). This extends the focus of previous research that has evaluated only the direct impact of customer misbehavior on others' satisfaction or service provider evaluation (e.g., Bitner, Booms, and Tetreault 1990; Grove and Fisk 1997). Our research demonstrates that indirect misbehavior can also have severe negative effects.

Third, unlike existing literature on customer misbehavior, we specifically consider variables that influence its contagion. We identified the brand of the accessed product, anonymity of the accessed product's owner, and communal identification among customers as three moderators. Thereby, we add to broken windows theory by revealing a mechanism to achieve what has been termed as "fixing broken windows" (Kelling and Coles 1997, p. 236). Although the theory proposes community ties to buffer the spreading of disorder, possible reversing mechanisms have not been considered. Our results show that in a setting with high communal identification, customers seem to act for the betterment of the community by removing the signs of previous misbehavior.

Finally, our investigation adds to the growing research on access-based services. As the industry's importance increases, questions arise regarding customer-object relationships (Durgee and O'Connor 1995). Bardhi and Eckhardt (2012) discuss the relevance of customer misbehavior in access-based services. Our study highlights this relevance and offers the first quantitative empirical study in this field.

\section{Managerial Implications}

Our findings have important managerial implications. Generally speaking, managers dealing with indirect customer misbehavior should expect it to negatively affect other customers' behaviors. One customer who misbehaves can cause other 
customers to engage in similar misconduct. Therefore, misbehaving customers and the physical outcomes of their misbehavior should be minimized to keep other customers from being affected and to prevent a vicious circle.

Companies providing access-based services may find it difficult to detect misbehavior before customers do. Our results suggest three approaches that service providers can adopt to reduce the contagious effects of misbehavior without requiring that the product be checked in-between uses. First, companies should use enduring product-related signals, such as a strong brand, to reduce the contagiousness of misbehavior. This requires that service providers ensure regular investments in brand building and product maintenance. Second, managers should decrease the service provider's level of anonymity. Rather than being perceived as an impersonal entity that owns the accessed car, companies should aim for a more personal customer relationship to reduce or even offset the spreading of customer misbehavior. One possibility would be featuring employees, or even the CEO, of the service in virtual customer contacts (e.g., company website and e-mail). Moreover, the lack of personal contact between customers and firm representatives could, for instance, be mitigated via avatars that greet customers when entering the vehicle. This approach would be in line with previous research that found virtual sales assistants to increase trust, satisfaction, attitudes, and purchase intentions (Holzwarth, Janiszewski, and Neumann 2006; Keeling, McGoldrick, and Beatty 2010). Third, our findings suggest that enhancing identification with the community is an effective mechanism for reversing the contagiousness of misbehavior. Schaefers (2013) found that customers of access-based services use these services because they desire to interact and build community with other customers. Our results indicate that service providers should respond to this desire and build a sense of brand community. Such activities should be of high priority for decreasing misbehavior.

Our results gain additional relevance with regard to the common practice of using regulation (e.g., fines) or remote surveillance (e.g., vehicle tracking) for addressing misbehavior (Bardhi and Eckhardt 2012). This requires monitoring and enforcement and may generate negative feelings that customers are being watched or are distrusted. Although regulations may deter customers from misbehaving, some level of misbehavior may still occur. Our results offer a complementary approach to address misbehavior contagion. The moderators we investigated can be regarded as suitable levers to address misbehavior via social responsibility. Instead of investing in surveillance infrastructure, such as video cameras in the vehicles, service providers should first implement the approaches outlined previously to decrease misbehavior contagion.

\section{Limitations and Future Research Opportunities}

Certain limitations should be considered when interpreting the results. We focused on only one access-based business model - car sharing. It is one of the most well-known and economically relevant examples (Botsman and Rogers 2010), but companies offering access to other goods such as fashion items face similar customer misbehavior. Our approach to address contagious effects of misbehavior should apply to access-based services in general. We hope further research compares the suitability of a more personal relationship and of product-related cues across different types of access-based services.

Despite the high external validity of our field study, the relatively homogeneous sample of student customers limited our analysis to respondents with a generally high level of communal identification. As outlined in the discussion, this sample structure likely explains the nonsignificant contagious effect among customers with lower levels of communal identification. Although we realize the large efforts required for conducting a field study on customer misbehavior, future research should try to replicate our analysis in a more anonymous setting or manipulate communal identification to validate the contagious effect of previous customer misbehavior.

Based on broken windows theory, we focused our investigation on product-related cues and anonymity as moderators. In addition to these theoretically derived factors, existing access-based business models have implemented fines as well as incentives to influence customer behavior (Bardhi and Eckhardt 2012). Future studies could investigate these traditional control mechanisms in detail, for instance, by comparing monetary to nonmonetary fines/incentives. Further research should consider the interplay between such punitive actions and the approaches we have identified. Other studies could also compare to what extent the factors we have investigated can insulate the service provider from significant changes in customer satisfaction compared to fine/incentive structures.

Related to the implementation of monitoring procedures is the role of misbehavior detection. Fisk et al. (2010) list the risk of being detected as an inhibitor of misbehavior. As we outlined earlier, the nature of access-based services-specifically, the fact that products are commonly accessed without supervision and interim return to the service provider-leads to smaller chances of misbehavior being detected and attributed to its originator compared to other services. Therefore, questions arise as to whether detection likelihood actually influences misbehavior contagion and how service providers may address this aspect. For instance, in addition to punitive measures, the perceived risk of being detected might be influenced by customers' perceptions of social norms, offering a conceptual link between broken windows theory and monitoring procedures. Future research could thus investigate perceived detection likelihood as an additional mediator of misbehavior contagion.

We have investigated factors that affect misbehavior contagion which are within a service provider's control. At the same time, it is likely that customer misbehavior as well as 
its contagiousness is influenced by situational variables. For example, researchers can explore the influence of customers' consumption goals (i.e., hedonic vs. utilitarian) of a specific access-based service use. Additionally, as we only investigated indirect misbehavior contagion, future studies should examine the impact of direct misbehavior, that is, misconduct in the presence of other customers (e.g., unknown others or peers) in the consumption situation.

Finally, it would be worthwhile for future research to study whom customers hold responsible for misbehavior. In the opening product review, it is unclear who the cus- tomer blames for the condition of the accessed vehicle. Experiencing previous misbehavior could exert different contagious effects depending on whether customers blame previous customers for their misbehavior or blame the service provider for failing to remove signs of previous misbehavior.

Overall, we believe that while our investigation answers important questions, a multitude of relevant questions about customer misbehavior contagiousness in access-based services remain that offer the potential to expand knowledge in this domain.

\section{Appendix}

Table AI. Items and Reliability Measures (Study I/Study 2/Study 3).

\begin{tabular}{|c|c|c|c|c|c|}
\hline & Cronbach's $\alpha$ & $\begin{array}{l}\text { Construct } \\
\text { Reliability }\end{array}$ & AVE & $\begin{array}{l}\text { Factor } \\
\text { Loadings }\end{array}$ & $\begin{array}{l}\text { Indicator } \\
\text { Reliability }\end{array}$ \\
\hline \multicolumn{4}{|c|}{$\begin{array}{l}\mathrm{x}_{1} \text { : I would not clean the car before returning it, even if I made it dirty } \\
\mathrm{x}_{2} \text { : I would not notify [the service provider/the owner] about a scratch I made in the car } \\
\mathrm{x}_{3} \text { : I would leave my trash in the car } \\
\mathrm{x}_{4} \text { : I would not notify [the service provider/the owner] if I slightly damaged the side mirror } \\
\mathrm{x}_{5} \text { : I would treat the car in a way that others may find unacceptable }\end{array}$} & $\begin{array}{l}.61 / .59 /- \\
.77 / .73 /- \\
.69 / .75 /- \\
.85 / .81 /- \\
.52 / .54 /-\end{array}$ & $\begin{array}{l}.33 / .32 /- \\
.57 / .56 /- \\
.61 / .73 /- \\
.78 / .73 /- \\
.27 / .26 /-\end{array}$ \\
\hline $\begin{array}{l}\text { Communal identification (Rindfleisch, Burroughs, and Wong 2009) } \\
\mathrm{x}_{15} \text { : I really identify with other people who use [service provider] } \\
\mathrm{x}_{16}: \text { I really feel like I almost belong to a club with other [service prc } \\
\mathrm{x}_{17}: \text { [Service provider] is used by people like me } \\
\mathrm{x}_{18} \text { : I feel a deep connection with others who use [service provider] }\end{array}$ & ider] users & & & & \\
\hline $\begin{array}{l}\text { Altruism (Rushton, Chrisjohn, and Fekken I98I) } \\
x_{19}: \text { I have given money to a charity } \\
x_{20}: \text { I have donated blood } \\
x_{21}: \text { I have delayed an elevator and held the door open for a strang } \\
\text { CFA model fit Study I: } \chi^{2}(74)=199.35 ; \chi^{2} / d f=2.69 ; \text { RMSEA }=.068 \\
\text { CFA model fit Study } 2: \chi^{2}(74)=258.05 ; \chi^{2} / d f=3.49 ; \text { RMSEA }=.08\end{array}$ & $\begin{array}{l}\text { SRMR }=.047 ; \\
\text { SRMR }=.061 ;\end{array}$ & $=.93 ; \mathrm{N}$ & & & \\
\hline
\end{tabular}

Note. Misbehavior scale employed in Studies I and 2 only, communal identification and altruism scale employed in Study 3 only. For Study 3 (field experiment), actual misbehavior was analyzed instead of self-reported misbehavior. CFA = confirmatory factor analysis; CFI = comparative fit index; RMSEA = Root Mean Square Error of Approximation; SRMR = standardized root mean square residual; NNFI = nonnormed fit index; $\mathrm{AVE}=$ average variance extracted. 


\section{Appendix B}

Table B I. Stimuli Used in Studies I and 2.

\section{A: Study I}

[Introductory text, all participants]

You are a registered customer of the car sharing company AUTOshare that offers short-term rental of cars in your city. Now you rent a vehicle from AUTOshare. You pick up the car where the previous user parked it. By holding your AUTOshare card against the card reader in the windshield you unlock the vehicle, which is a [brand] car. At the beginning of your rental the condition of the vehicle is as follows:

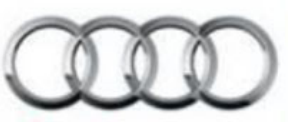

Audi
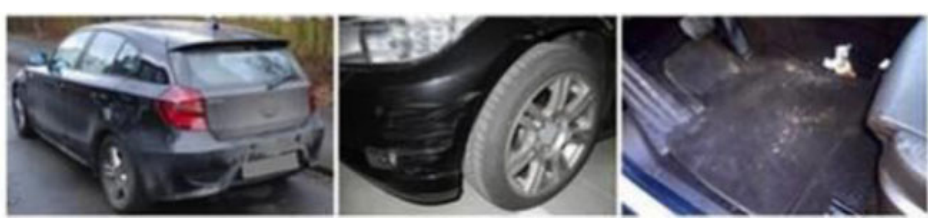

Previous misbehavior and strong brand condition

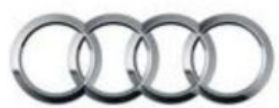

Audi
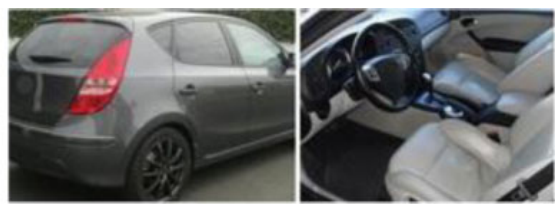

No previous misbehavior and strong brand condition

\section{B: Study 2}

[Introductory text, anonymous owner condition]

You are a registered customer of the car sharing company AUTOshare that offers short-term rental of cars in your city. Now you rent a vehicle from AUTOshare. You pick up the car where the previous user parked it. By holding your AUTOshare card against the card reader in the windshield you unlock the vehicle. At the beginning of your rental the condition of the vehicle is as follows:

[Introductory text, identified owner condition]

You are a registered member of the Internet peer-to-peer car sharing community AUTOshare that lets car owners rent out their vehicles to others. Now you are searching for a vehicle for short-term rental. You find another member close-by with whom you agree on a place and time to meet and pick up the car. At the beginning of your rental the condition of the vehicle is as follows:
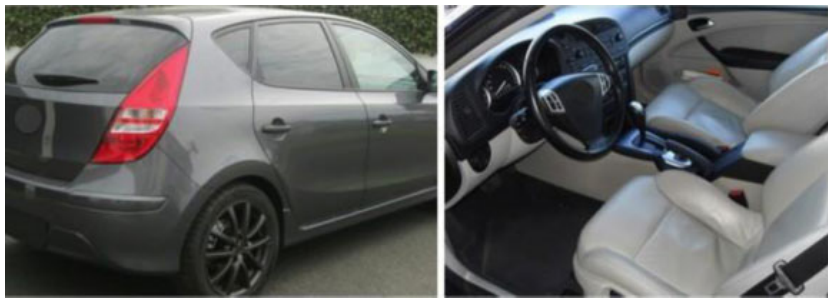

No previous misbehavior condition
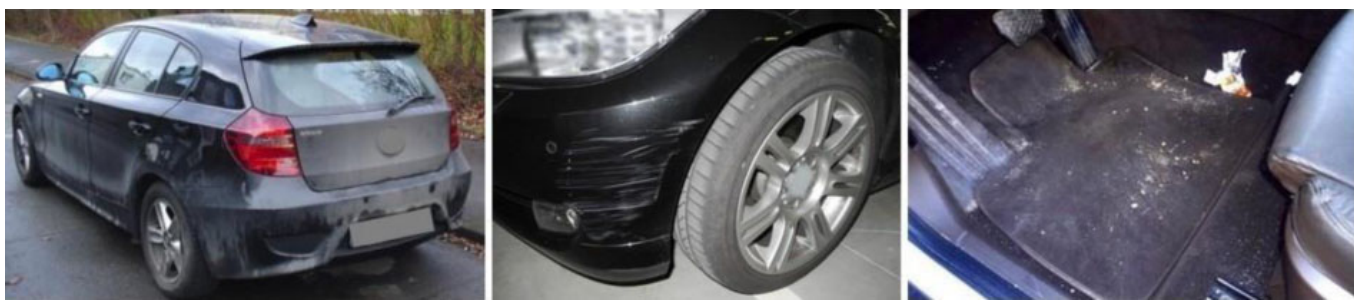

Previous misbehavior condition 


\section{Acknowledgments}

The authors would like to thank one anonymous reviewer for suggesting the possibility of a reversed contagious effect. The authors thank Johannes Boegershausen and Janet Wagner as well as the editor and the review team for helpful comments on earlier versions of the manuscript.

\section{Declaration of Conflicting Interests}

The author(s) declared no potential conflicts of interest with respect to the research, authorship, and/or publication of this article.

\section{Funding}

The author(s) received no financial support for the research, authorship, and/or publication of this article.

\section{References}

Bardhi, Fleura and Giana M. Eckhardt (2012), "Access-Based Consumption: The Case of Car Sharing," Journal of Consumer Research, 39 (4), 881-898.

Belk, Russell (2010), "Sharing," Journal of Consumer Research, 36 (5), 715-734.

Bitner, Mary Jo, Bernard H. Booms, and Lois A. Mohr (1994), "Critical Service Encounters: The Employee's Viewpoint," Journal of Marketing, 58 (4), 95-106.

Bitner, Mary Jo, Bernard H. Booms, and Mary Stanfield Tetreault (1990), "The Service Encounter: Diagnosing Favorable and Unfavorable Incidents," Journal of Marketing, 54 (1), 71-84.

Botsman, Rachel and Roo Rogers (2010), What's Mine Is Yours: The Rise of Collaborative Consumption. New York, NY: HarperBusiness.

Chaurand, Nadine and Markus Brauer (2008), "What Determines Social Control? People's Reactions to Counternormative Behaviors in Urban Environments1," Journal of Applied Social Psychology, 38 (7), 1689-1715.

Cox, Dena, Anthony D. Cox, and George P. Moschis (1990), "When Consumer Behavior Goes Bad: An Investigation of Adolescent Shoplifting," Journal of Consumer Research, 17 (2), 149-159.

Crossland, David (2011), "German Car Makers See Car-Sharing as Way to Revive Sales," in The National, Vol. 7/28/2011, (accessed September 21, 2011), [avilable at http://www.thenational.ae/ business/industry-insights/technology/german-car-makers-seecar-sharing-as-way-to-revive-sales].

Crowne, Douglas P. and David Marlowe (1960), "A New Scale of Social Desirable Independent of Psychopathology," Journal of Consulting Psychology, 24 (4), 349-354.

Dallimore, Karen S., Beverley A. Sparks, and Ken Butcher (2007), "The Influence of Angry Customer Outbursts on Service Providers' Facial Displays and Affective States," Journal of Service Research, 10 (1), 78-92.

Daunt, Kate L. and Lloyd C. Harris (2011), "Customers Acting Badly: Evidence from the Hospitality Industry," Journal of Business Research, 64 (10), 1034-1042.

Dodds, William B., Kent B. Monroe, and Dhruv Grewal (1991), "Effects of Price, Brand, and Store Information on Buyers' Product Evaluations," Journal of Marketing Research, 28 (3), 307-319.
Durgee, Jeffrey F. and Gina Colarelli O’Connor (1995), “An Exploration into Renting as Consumption Behavior," Psychology and Marketing, 12 (2), 89-104.

Eisenberger, Robert, Patrick Lynch, Justin Aselage, and Stephanie Rohdieck (2004), "Who Takes the Most Revenge? Individual Differences in Negative Reciprocity Norm Endorsement," Personality and Social Psychology Bulletin, 30 (6), 787-799.

Firnkorn, Jörg and Martin Müller (2011), "What Will Be the Environmental Effects of New Free-Floating Car-Sharing Systems? The Case of Car2go in Ulm," Ecological Economics, 70 (8), 1519-1528.

Fisk, Ray, Stephen Grove, Lloyd C. Harris, Dominique A. Keeffe, Kate L. Daunt, Rebekah Russell-Bennett, and Jochen Wirtz (2010), "Customers Behaving Badly: A State of the Art Review, Research Agenda and Implications for Practitioners," Journal of Services Marketing, 24 (6), 417-429.

Fornell, Claes and David F. Larcker (1981), "Evaluating Structural Equation Models with Unobservable Variables and Measurement Error," Journal of Marketing Research, 18 (1), 39-50.

Fullerton, Ronald A. and Girish Punj (2004), "Repercussions of Promoting an Ideology of Consumption: Consumer Misbehavior," Journal of Business Research, 57 (11), 1239-1249.

Gino, Francesca, Shahar Ayal, and Dan Ariely (2009), "Contagion and Differentiation in Unethical Behavior," Psychological Science, 20 (3), 393-398.

Gong, Taeshik, Youjae Yi, and Jin Nam Choi (2014), “Helping Employees Deal with Dysfunctional Customers: The Underlying Employee Perceived Justice Mechanism," Journal of Service Research, 17 (1), 102-116.

Grove, Stephen J. and Raymond P. Fisk (1997), “The Impact of Other Customers on Service Experiences: A Critical Incident Examination of 'Getting Along," Journal of Retailing, 73 (1), 63-85.

Harcourt, Bernard E. (2009), Illusion of Order: The False Promise of Broken Windows Policing. Boston, MA: Harvard University Press.

Harris, Lloyd C. and Kate L. Daunt (2011), "Deviant Customer Behaviour: A Study of Techniques of Neutralisation," Journal of Marketing Management, 27 (7/8), 834-853.

Harris, Lloyd C. and Kate L. Reynolds (2003), "The Consequences of Dysfunctional Customer Behavior," Journal of Service Research, 6 (2), 144-161.

Hayes, Andrew F. (2013), An Introduction to Mediation, Moderation, and Conditional Process Analysis: A Regression-Based Approach. New York, NY: Guilford Press.

Hennig-Thurau, Thorsten, Markus Groth, Michael Paul, and Dwayne D. Gremler (2006), “Are All Smiles Created Equal? How Emotional Contagion and Emotional Labor Affect Service Relationships," Journal of Marketing, 70 (3), 58-73.

Holzwarth, Martin, Chris Janiszewski, and Marcus M. Neumann (2006), "The Influence of Avatars on Online Consumer Shopping Behavior," Journal of Marketing, 70 (4), 19-36.

Irwin, Julie R. and Gary H. McClelland (2001), "Misleading Heuristics and Moderated Multiple Regression Models," Journal of Marketing Research, 38 (1), 100-109.

Johnson, Michael D., Andreas Herrmann, and Frank Huber (1998), "Growth through Product-Sharing Services," Journal of Service Research, 1 (2), 167-177. 
Johnson, Palmer O. and Leo C. Fay (1950), "The Johnson-Neyman Technique, Its Theory and Application," Psychometrika, 15 (4), 349-367.

Jones, Donald R. and M. B. Jones (1992), "Behavioral Contagion in Sibships," Journal of Psychiatric Research, 26 (2), 149-164.

Keeling, Kathleen, Peter McGoldrick, and Susan Beatty (2010), "Avatars as Salespeople: Communication Style, Trust, and Intentions," Journal of Business Research, 63 (8), 793-800.

Keizer, Kees, Siegwart Lindenberg, and Linda Steg (2008), "The Spreading of Disorder," Science, 322 (5908), 1681-1685.

Keizer, Kees, Siegwart Lindenberg, and Linda Steg (2013), "The Importance of Demonstratively Restoring Order," PLoS One, 8 (6), e65137.

Kelling, George L. and Catherine M. Coles (1997), Fixing Broken Windows: Restoring Order and Reducing Crime in Our Communities. New York, NY: Simon \& Schuster.

Kelling, George L. and James Q. Wilson (1982), "Broken Windowsthe Police and Neighborhood Safety," The Atlantic Monthly, 249 (March), 29-38.

Kozinets, Robert V., Kristine de Valck, Andrea C. Wojnicki, and Sarah J. S. Wilner (2010), "Networked Narratives: Understanding Word-of-Mouth Marketing in Online Communities," Journal of Marketing, 74 (2), 71-89.

Leismann, Kristin, Martina Schmitt, Holger Rohn, and Carolin Baedeker (2013), "Collaborative Consumption: Towards a ResourceSaving Consumption Culture," Resources, 2 (3), 184-203.

Lovelock, Christopher H. (1994), Product Plus: How Product + Service $=$ Competitive Advantage. New York, NY: McGraw-Hill.

Lovelock, Christopher H. and Evert Gummesson (2004), "Wither Services Marketing? In Search of a New Paradigm and Fresh Perspectives," Journal of Service Research, 7 (1), 20-41.

Luong, Alexandra (2005), "Affective Service Display and Customer Mood," Journal of Service Research, 8 (2), 117-130.

McColl-Kennedy, Janet R., Paul G. Patterson, Amy K. Smith, and Michael K. Brady (2009), "Customer Rage Episodes: Emotions, Expressions and Behaviors," Journal of Retailing, 85 (2), 222-237.

Moeller, Sabine and Kristina Wittkowski (2010), "The Burdens of Ownership: Reasons for Preferring Renting," Managing Service Quality, 20 (2), 176-191.

Mont, O. K. (2002), "Clarifying the Concept of Product-Service System," Journal of Cleaner Production, 10 (3), 237-245.

Moore, Robert, Melissa Moore, L., and Michael Capella (2005), "The Impact of Customer-to-Customer Interactions in a High Personal Contact Service Setting," Journal of Services Marketing, 19 (7), 482-491.

Muniz, Albert M. Jr., and Thomas C. O'Guinn (2001), "Brand Community," Journal of Consumer Research, 27 (4), 412-432.

Netemeyer, Richard G., William O. Bearden, and Subhash Sharma (2003), Scaling Procedures: Issues and Applications. Thousand Oaks, CA: Sage.

Nugier, Armelle, Peggy Chekroun, Karine Pierre, and Paula M. Niedenthal (2009), "Group Membership Influences Social Control of Perpetrators of Uncivil Behaviors," European Journal of Social Psychology, 39 (6), 1126-1134.

Rindfleisch, Aric, James E. Burroughs, and Nancy Wong (2009), "The Safety of Objects: Materialism, Existential Insecurity, and
Brand Connection," Journal of Consumer Research, 36 (1), $1-16$.

Ross, Catherine E. and Sung Joon Jang (2000), "Neighborhood Disorder, Fear, and Mistrust: The Buffering Role of Social Ties with Neighbors," American Journal of Community Psychology, 28 (4), 401-420.

Rushton, Philippe J., Roland D. Chrisjohn, and Cynthia G. Fekken (1981), "The Altruistic Personality and the Self-Report Altruism Scale," Personality and Individual Differences, 2 (4), 293-302.

Sampson, Robert J., Jeffrey D. Morenoff, and Thomas Gannon-Rowley (2002), “Assessing 'Neighborhood Effects': Social Processes and New Directions in Research," Annual Review of Sociology, 28 (1), 443-478.

Schaefers, Tobias (2013), "Exploring Carsharing Usage Motives: A Hierarchical Means-End Chain Analysis," Transportation Research Part A: Policy and Practice, 47 (1), 69-77.

Schaefers, Tobias, Stephanie J Lawson, and Monika Kukar-Kinney (2015), "How the Burdens of Ownership Promote Consumer Usage of Access-Based Services," Marketing Letters, (Online First, April 11, 2015), [available at http://dx.doi.org/10.1007/ s11002-015-9366-x].

Smith, Jonathan A., Paul Flowers, and Michael Larkin (2009), Interpretative Phenomenological Analysis-Theory, Method and Research. London, England: Sage.

Teas, R. Kenneth and Sanjeev Agarwal (2000), “The Effects of Extrinsic Product Cues on Consumers' Perceptions of Quality, Sacrifice, and Value," Journal of the Academy of Marketing Science, 28 (2), 278-290.

Verhoef, Peter C., Katherine N. Lemon, A. Parasuraman, Anne Roggeveen, Michael Tsiros, and Leonard A. Schlesinger (2009), "Customer Experience Creation: Determinants, Dynamics and Management Strategies," Journal of Retailing, 85 (1), 31-41.

Wilcox, Pamela, Neil Quisenberry, Debra T. Cabrera, and Shayne Jones (2004), "Busy Places and Broken Windows? Toward Defining the Role of Physical Structure and Process in Community Crime Models," Sociological Quarterly, 45 (2), 185-207.

Wirtz, Jochen and Doreen Kum (2004), "Consumer Cheating on Service Guarantees," Journal of the Academy of Marketing Science, 32 (2), 159-175.

Wittkowski, Kristina, Sabine Moeller, and Jochen Wirtz (2013), "Firms' Intentions to Use Nonownership Services," Journal of Service Research, 16 (2), 171-185.

Xu, Yili, Mora L. Fiedler, and Karl H. Flaming (2005), "Discovering the Impact of Community Policing: The Broken Windows Thesis, Collective Efficacy, and Citizens' Judgment," Journal of Research in Crime and Delinquency, 42 (2), 147-186.

\section{Author Biographies}

Tobias Schaefers is an assistant professor of Marketing at the TU Dortmund University, Germany. His research focuses on accessbased services, technology-enabled interactions between companies and (private as well as organizational) customers, sponsoring, and sales. His work has appeared in Journal of Interactive Marketing, Marketing Letters, Psychology \& Marketing, and European Journal of Marketing, among others. 
Kristina Wittkowski is a postdoctoral researcher at the Aalto University School of Business, Finland. Her research focuses on access-based or nonownership services, the downsides of cocreation, and customer participation in health care services. Her work has been published in Journal of Service Research, Journal of the Academy of Marketing Science, and Managing Service Quality. She serves on the editorial review board of Journal of Service Theory and Practice (formerly Managing Service Quality).

Sabine Benoit (née Moeller) is a professor of marketing at the Roehampton Business School, University of Roehampton, London, UK. Her research focuses on Service and Retail Marketing, in particular on-the-go consumption, collaborative value creation, access-based or nonownership services, as well as consumer perceptions of sustainability. Her work has been published in Journal of Service Research,
Journal of Services Marketing, Psychology \& Marketing, and Journal of Operations Management, among others. She serves on the editorial review boards of Journal of Service Research, Journal of Services Marketing, Journal of Service Management, and Journal of Business Research.

Rosellina Ferraro is an associate professor of Marketing at the Robert H. Smith School of Business, University of Maryland, USA. Her research focuses on consumer behavior, and specifically, the effects of nonconscious social influence on choice and preference and the effects of the social environment on consumption behavior. Her work has been published in Journal of Consumer Research, Journal of Marketing Research, Journal of Marketing, Marketing Science, and Journal of Consumer Psychology. She serves on the editorial review board of Journal of Consumer Research and Journal of Consumer Psychology. 